\title{
Orbital and adnexal tuberculosis: a case series from a South Indian population
}

\author{
Kalpana Babu ${ }^{1,2^{*}}$, Moupia Mukhopadhyay ${ }^{1,2}$, Soumya S Bhat ${ }^{1,2}$ and JT Chinmayee ${ }^{1,2}$
}

\begin{abstract}
Background: Orbital tuberculosis (OTb) is rare and may be regarded as a manifestation of extrapulmonary tuberculosis. We report an interesting case series of six patients with varied presentations of orbital and adnexal tuberculosis in a South Indian patient population.

Results: A retrospective, interventional case series of six patients diagnosed with orbital and adnexal tuberculosis on the basis of clinical, radiological and histopathological evaluations between 2010 and 2013 was performed. Among the six patients with histopathologically proven OTb, five were women. The varied presentations included tubercular dacryoadenitis (two cases), classical periostitis (two cases), OTb with bone involvement (one case) and ocular adnexal tuberculosis (one case). Systemic involvement was seen in one case. All cases were treated with a regimen of antitubercular therapy (ATT).
\end{abstract}

Conclusions: OTb, though rare, should form a part of the differential diagnosis of orbital lesions in a high tuberculosis (TB) endemic country like ours. Biopsy still remains the mainstay of diagnosis.

Keywords: Orbital tuberculosis; Mycobacterium tuberculosis; Proptosis; Antitubercular therapy

\section{Background}

Recent years have demonstrated an increasing trend in the diagnosis of ocular tuberculosis, due to the increased awareness of the disease and availability of better diagnostic modalities. In contrast, orbital tuberculosis $(\mathrm{OTb})$ is rare but still forms an important differential diagnosis of orbital mass lesions in a high tuberculosis (TB) endemic setting like ours.

OTb represents an extrapulmonary form of tuberculosis and may arise either by haematogenous route or spread directly from the paranasal sinuses. Diagnosis is usually by biopsy and supported by ancillary investigations like the Mantoux test, radiology and molecular diagnostic techniques like the polymerase chain reaction (PCR). In this case series, we look at the clinical profile of six patients diagnosed with orbital and adnexal tuberculosis.

\footnotetext{
* Correspondence: kalpana@prabhaeyeclinic.com

${ }^{1}$ Vittala International Institute of Ophthalmology, Bangalore 560085, India ${ }^{2}$ Prabha Eye Clinic and Research Centre, 504, 40th Cross, Jayanagar 8th Block, Bangalore 560070, India
}

\section{Methods}

Retrospective chart review of six patients with histopathologically proven OTb between 2010 and 2013 was performed.

\section{Results}

Five out of the six cases in our series were women and in the middle age group (range, 15 to 56 years; mean, 38 years).

\section{Case 1}

A 15-year-old girl presented with a history of painless, progressive swelling on the left side of the face of 2 months duration. She had a history of drainage of abscesses in the neck and arm, following which she was on antitubercular therapy for 3 months, which she eventually discontinued abruptly. On examination, fullness along the left lateral orbital rim with ptosis (especially laterally) and limitation of abduction in the left eye were noted (Figure 1A). Her BCVA was 6/6 in both eyes. Slit lamp, fundus and intraocular pressure evaluations were normal in both eyes. Systemic examination revealed scars in the supraclavicular region and arm (Figure 1B). Computed tomography $(\mathrm{CT})$ of the orbits revealed a well-defined

\section{它 Springer}



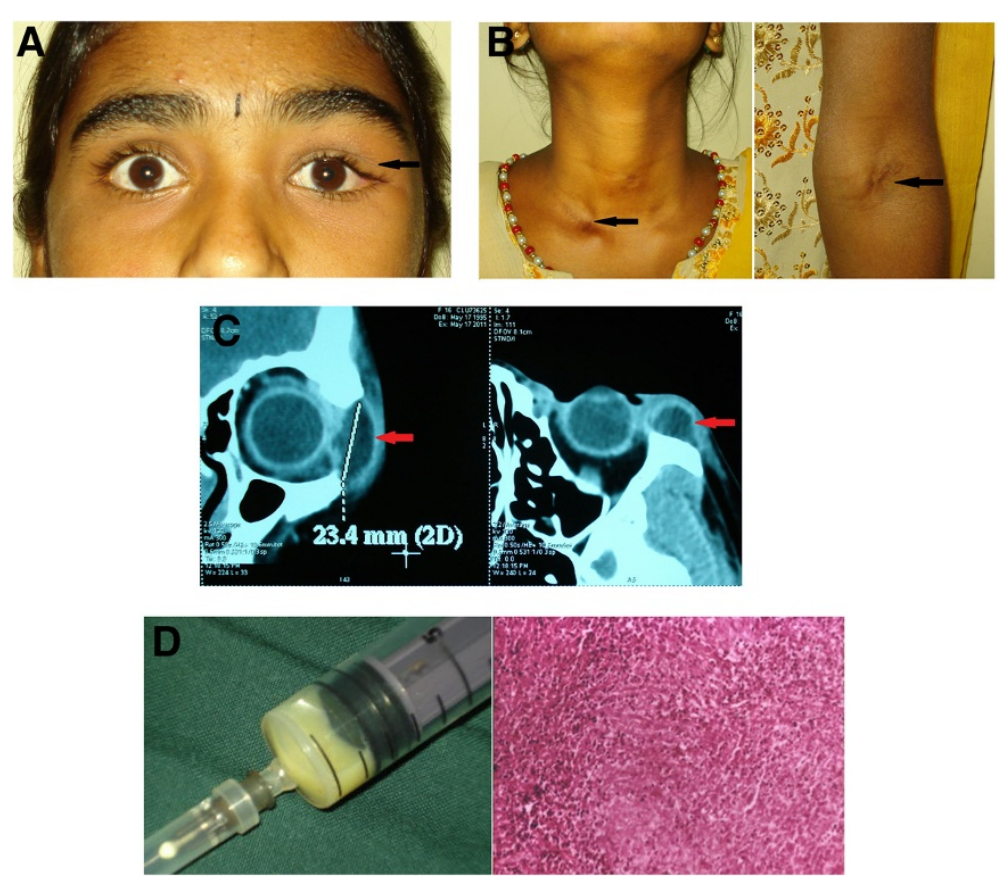

Figure 1 Examination results of case 1. (A) Face photograph of case 1 showing fullness along the lateral orbital rim with ptosis especially laterally (arrow). (B) External photograph showing sites of abscess drainage (scars) in the supraclavicular region and arm (arrows). (C) Computed tomography scan of the orbits showing lytic lesion in the bone with sequestration. (D) Photograph showing the pus collected and the chronic granulomatous inflammation on histopathology showing caseation necrosis.

lytic lesion along the lateral orbital wall with central sequestrum and associated peripherally enhancing abscess with minimal periosteal reaction suggestive of osteomyelitis (Figure 1C). Laboratory investigations revealed an increased erythrocyte sedimentation rate (ESR) of $60 \mathrm{~mm} / \mathrm{h}$, a positive Mantoux test and a normal chest $\mathrm{X}$-ray. The abscess was drained, and the wall of the abscess cavity was sent for microbiological and histopathological examination. Chronic granulomatous inflammation with caseation necrosis was seen on histopathology (Figure 1D). Although the Gomori methenamine silver (GMS) staining, acid fast bacilli (AFB) staining and culture for Mycobacterium tuberculosis (MTb) were negative, PCR was positive for MTb. She was started on a second-line antitubercular therapy (ATT) which included daily intramuscular injections of streptomycin $0.75 \mathrm{mg}$ for 6 months, ethionamide tablet $250 \mathrm{mg}$ twice daily, cycloserine tablet $250 \mathrm{mg}$ twice daily and ofloxacin tablet $400 \mathrm{mg}$ once daily for 1.5 years. At the last follow-up, the lesion at the lateral orbital rim had resolved completely.

\section{Case 2}

A 40-year-old lady presented with a swelling below the left eyebrow of 1 month duration. Examination revealed a firm, palpable mass in the region of the lacrimal gland (Figure 2A). Ocular evaluation was normal in both eyes.
CT scan showed diffuse enlargement of the lacrimal gland with no bony remodelling or moulding around the globe (Figure 2B). The excised mass showed granulomatous inflammation with caseation necrosis on histopathology (Figure 2C). GMS, Ziehl-Neelson (ZN) staining and PCR for MTb were negative. Laboratory evaluation showed an ESR of $14 \mathrm{~mm} / \mathrm{h}$, normal chest radiography including CT thorax and a positive Mantoux test. She was started on four-drug regimen of ATT (isoniazid, rifampicin, ethambutol and pyrazinamide). At the end of 1 year, she is doing well with no recurrence of inflammation.

\section{Case 3}

A 56-year-old lady presented with swelling below the right eyebrow of 3 months duration. Examination revealed a diffuse, non-tender, firm mass in the lacrimal gland area (Figure 3A). CT scan showed diffuse enlargement of the lacrimal gland with no bony erosion or remodelling (Figure 3B). Excision biopsy showed granulomatous inflammation with caseation necrosis on histopathology (Figure 3C). GMS, ZN staining and PCR for MTb were negative. Laboratory evaluation showed an ESR of $20 \mathrm{~mm} / \mathrm{h}$, normal CT thorax and a positive Mantoux test. She was started on four-drug regimen of ATT (isoniazid, rifampicin, ethambutol and pyrazinamide). At the end of 1.5 years, she was doing well with no recurrence of mass. 

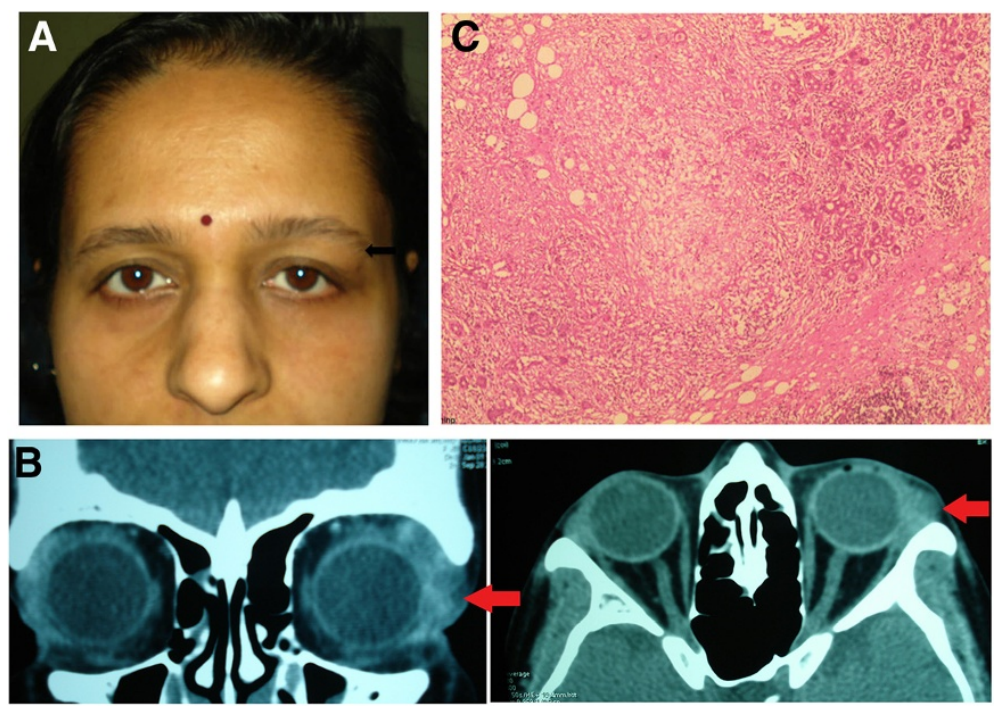

Figure 2 Examination results of case 2. (A) Face photograph of case 2 showing fullness below the lateral part of the left eye brow in the lacrimal gland area (arrow). (B) CT scan showing diffuse enlargement of the lacrimal gland, without bony erosion or bony remodelling. (C) Photomicrograph showing granulomatous inflammation with caseation necrosis (arrow).

\section{Case 4}

A 39-year-old lady was referred to our center for an indurated mass lesion with an overlying non-healing ulcer in the medial part of the right lower lid of 3 months duration (Figure 4A). CT scan of the orbits showed a soft tissue lesion in the anterior part of right medial orbit, and the lacrimal sac could not be delineated separately from the mass (Figure 4B). Histopathological examination of the abscess wall showed granulomatous inflammation with caseation (Figure 4C). ZN stain for acid fast bacilli was positive, while GMS stain for fungi was negative. Other laboratory investigations included an increase in the ESR (40 $\mathrm{mm} / \mathrm{h})$, a positive Mantoux test and a normal chest X-ray. Four-drug regimen of ATT (isoniazid,
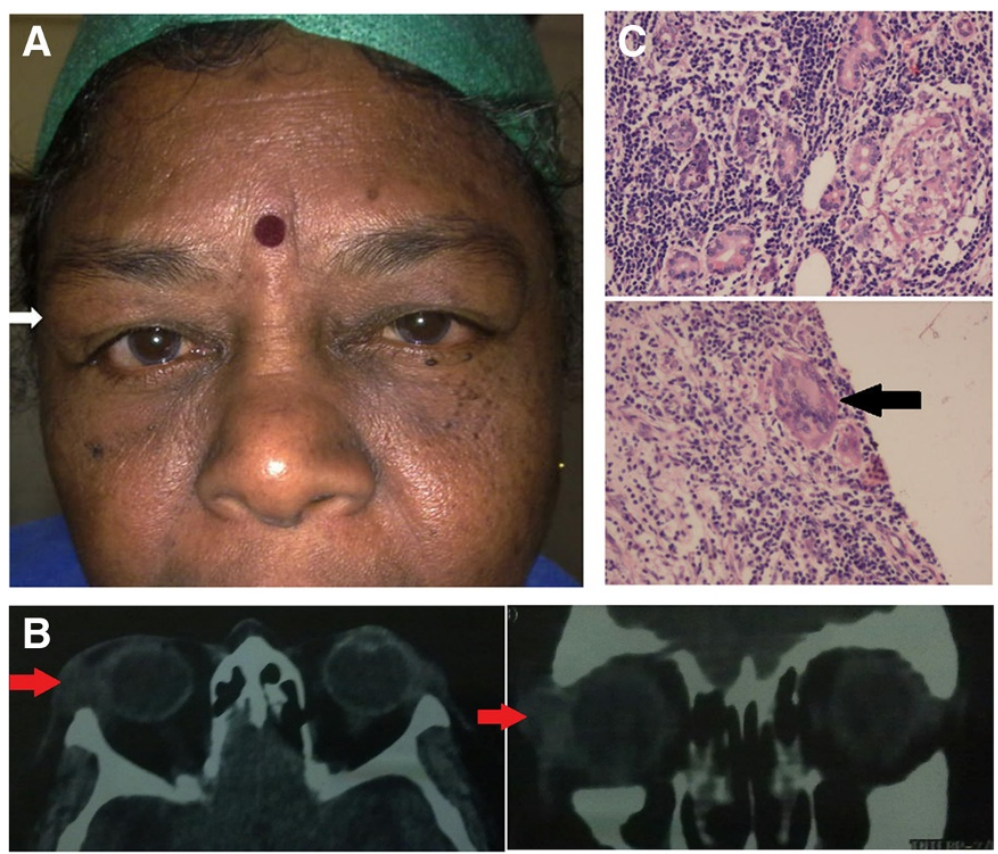

Figure 3 Examination results of case 3. (A) Face photograph of case 3 showing fullness below the lateral part of the right eye brow. (B) CT scan showing diffuse enlargement of the lacrimal gland (arrows) without any bony erosion or remodelling. (C) Microphotograph showing the chronic granulomatous inflammation with giant cells (arrow) and caseation necrosis (H\&E). 

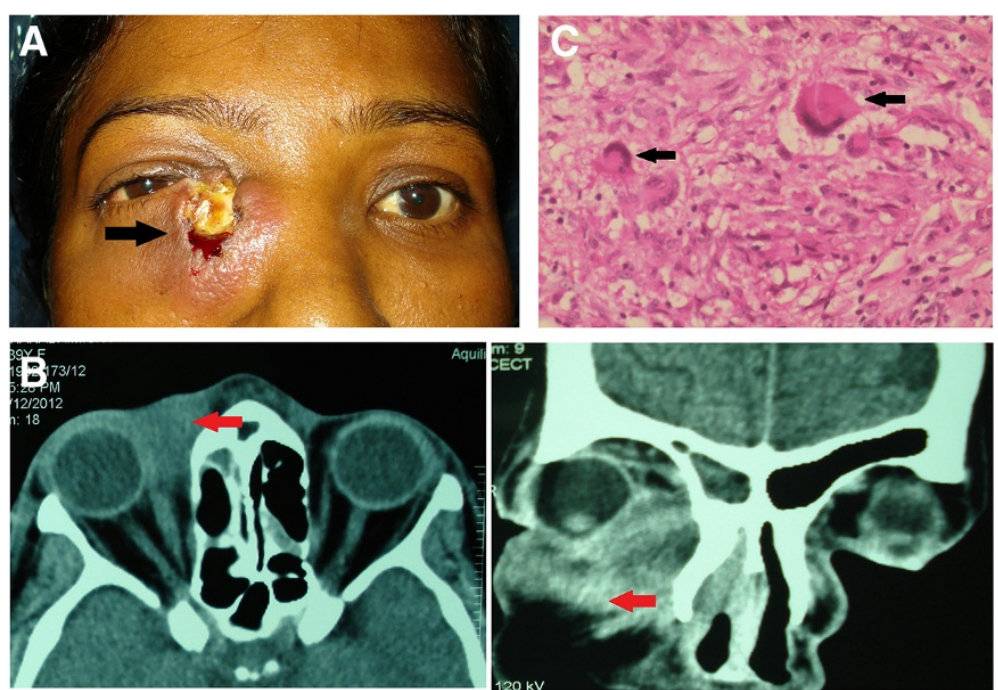

Figure 4 Examination results of case 4. (A) Face photograph of case 4 showing an indurated mass lesion with an overlying non-healing ulcer with discharge in the lacrimal sac area of the right eye (arrow). (B) CT scan showing soft tissue lesion in the anterior part of right medial orbit (arrow). (C) Photomicrograph showing chronic granulomatous inflammation with giant cells (arrow).

rifampicin, ethambutol and pyrazinamide) was initiated. She was doing well at the end of 6 months with no recurrence of mass or inflammation. She was lost to follow-up thereafter.

\section{Case 5}

A 28-year-old man presented with a swelling just below the left eyebrow area of 1-month duration. On examination, a firm, non-tender mass could be palpated in the inferior portion of the superior orbital rim (Figure 5A).
The rest of ocular evaluation was normal. CT scan orbits showed a soft tissue swelling inseparable from the left orbital rim (Figure 5B). Excision biopsy of this lesion revealed granulomatous inflammation with caseation (Figure 5C). GMS and ZN staining were negative, while PCR for MTb was positive. Other laboratory investigations showed an increase in ESR $(42 \mathrm{~mm} / \mathrm{h})$, normal CT thorax, positive Mantoux and QuantiFERON TB gold tests. He was started on four-drug regimen of ATT (isoniazid, rifampicin, ethambutol and pyrazinamide). At
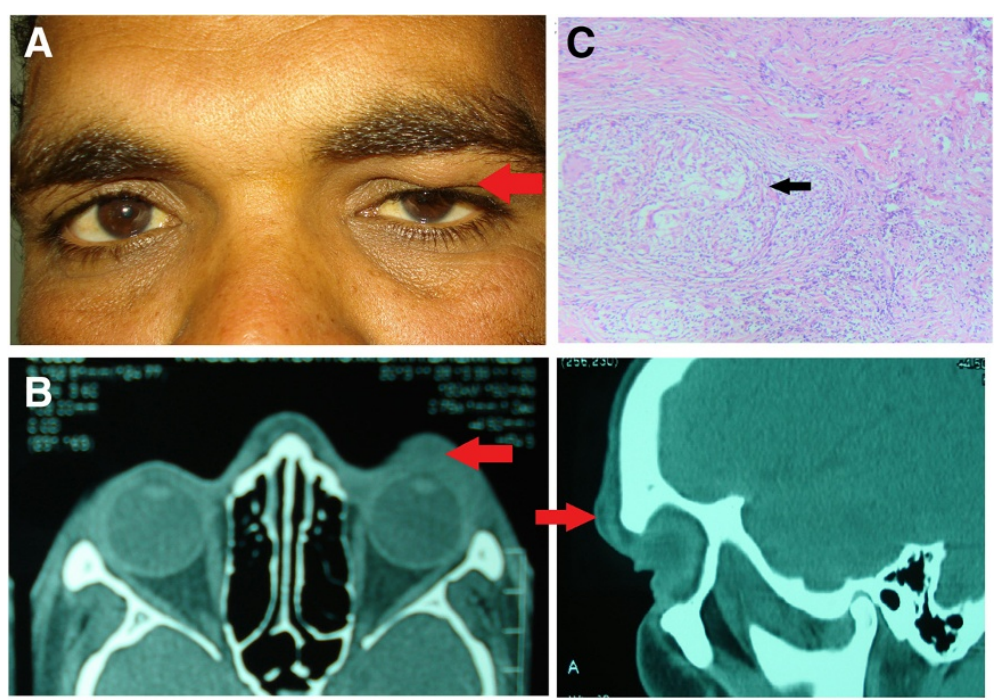

Figure 5 Examination results of case 5. (A) Face photograph of case 5 showing a preseptal swelling below the left superior orbital rim (arrow). (B) $\subset$ scan of the orbits showing soft tissue swelling in front of the superior orbital rim with no evidence of bony erosion (arrow). (C) Photomicrograph showing chronic granulomatous inflammation with giant cells and caseation necrosis (arrow). 
the last follow-up of 8 months, he is doing well with no recurrence of mass or lesion.

\section{Case 6}

A 50-year-old lady presented with a non-healing ulcer on the skin below the right lower eye lid of 4 months duration. On examination, she had a large non-healing ulcer on the right lower eyelid (Figure 6A). The ulcer was adherent to the underlying bone. CT scan of the orbits done earlier was not clear, and this lady could not afford a rescan. Histopathological examination of the excised ulcer tissue showed a granulomatous inflammation with giant cells and caseation (Figure 6B). ZN stain for AFB was positive (Figure 6C), while GMS stain for fungi was negative. There was no evidence of any malignant cells. Other laboratory evaluations showed an increase in ESR $(40 \mathrm{~mm} / \mathrm{h})$, a positive Mantoux test and a normal chest X-ray. She was started on the fourdrug regimen of antitubercular therapy, following which she was lost to follow-up.

Table 1 shows the salient features of the various clinical presentations in the series.

\section{Discussion}

OTb involving the lacrimal gland was first described by Abadie in 1881 [1]. Since then, around 84 cases have been described in literature (PubMed search) and around 50 cases from India. This explains the need to consider $\mathrm{OTb}$ as part of differential diagnosis in orbital lesions from a $\mathrm{Tb}$ endemic country like ours.

Five out of the six cases in our series were women and in the middle age group (range, 15 to 56 years; mean, 38 years). This series is comparable to the existing literature on OTb.

OTb can occur as a result of haematogenous spread or contiguous spread from the neighbouring paranasal sinuses. Varied manifestations of OTb excluding oculoadnexal tuberculosis can be grouped under five clinical groups: classical periostitis, orbital soft tissue tuberculoma or cold abscess with no bony destruction, OTb with evidence of bony involvement, orbital spread from paranasal sinuses and dacryoadenitis [1]. In our series, we found it difficult to categorise the type of OTb to any one particular group in three cases as it was difficult to figure out the initial process - whether it was a tuberculoma or a nodule followed by an ulceration or periostitis. Broadly depending on the final presentation, we could categorise them into tubercular dacryoadenitis (two cases), classical periostitis (two cases), OTb with bone involvement (one case) and ocular adnexal tuberculosis (one case). Only one of the six cases had a history of systemic tuberculosis and had received inadequate antitubercular therapy due to poor compliance. In four cases, the ESR was raised, while one case had only a marginal increase in ESR. All the
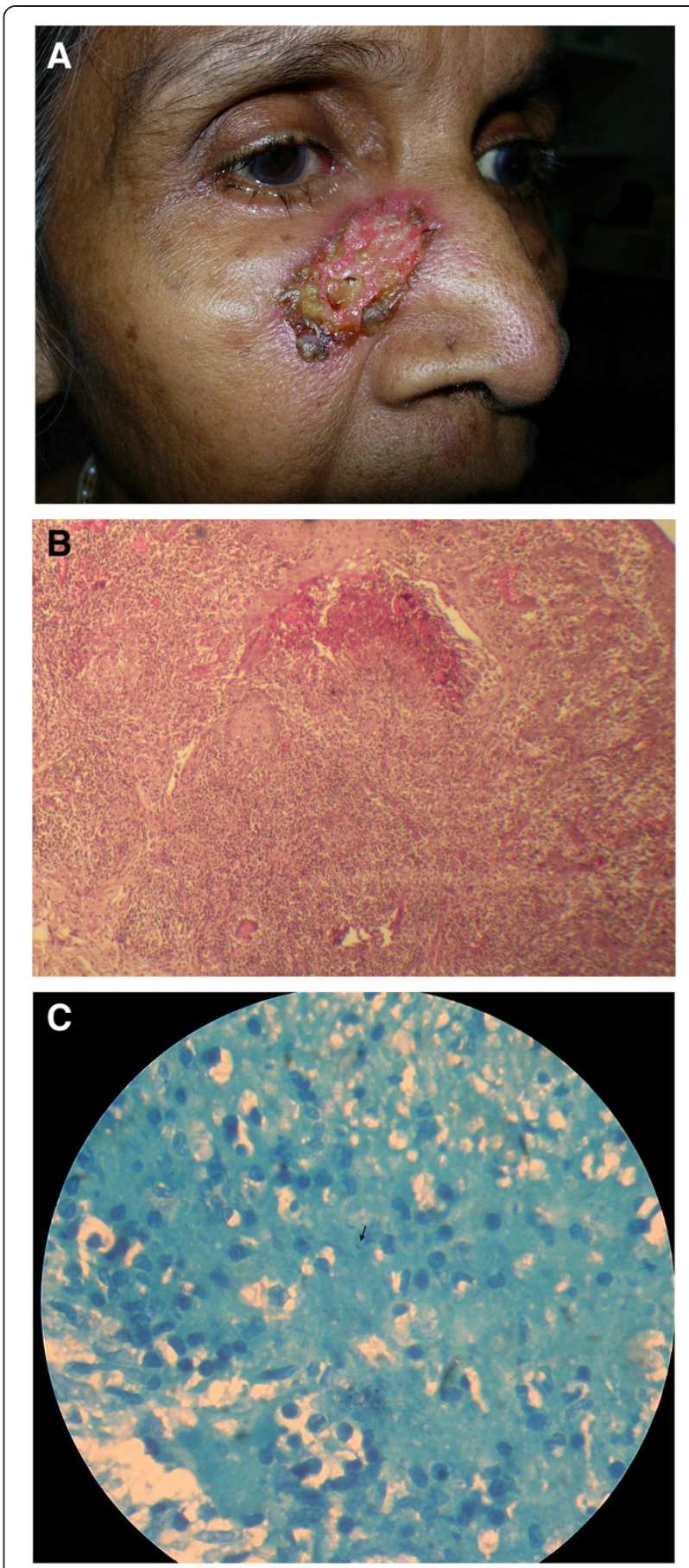

Figure 6 Examination results of case 6. (A) Face photograph of case 6 showing large ulceration on the right cheek below the right lower eyelid. Microphotograph showing (B) chronic granulomatous inflammation with giant cells and caseation necrosis and $\mathbf{( C )}$ positive acid fast bacilli indicated by an arrow.

cases elicited a positive Mantoux test and normal chest radiography (CT thorax was done in three cases).

The diagnosis of OTb was made by biopsy in all our cases. Although the recommended initial investigation 
Table 1 Salient features of clinical presentations in our series

\begin{tabular}{|c|c|c|c|c|c|c|c|c|}
\hline Case & Age/sex & Presentation & Systemic disease & Biopsy & ESR & CXR & Mantoux & ATT \\
\hline 1 & 15 years/F & Osteomyelitis & $\begin{array}{l}\text { Supraclavicular and } \\
\text { arm fistula scars -h/o } \\
\text { incomplete ATT }\end{array}$ & $\begin{array}{l}\text { PCR positive for MTB, AFB } \\
\text { negative; chronic granulomatous } \\
\text { inflammation with caseation }\end{array}$ & $\begin{array}{l}\text { Increased } \\
(60 \mathrm{~mm} / \mathrm{h})\end{array}$ & Normal & Positive & 2nd-line ATT \\
\hline 2 & 40 years/F & Dacryoadenitis & None & $\begin{array}{l}\text { Chronic granulomatous } \\
\text { inflammation with caseation; } \\
\text { PCR and AFB negative }\end{array}$ & $\begin{array}{l}\text { Normal } \\
(14 \mathrm{~mm} / \mathrm{h})\end{array}$ & Normal & Positive & 1st-line ATT \\
\hline 3 & 56 years/F & Dacryoadenitis & None & $\begin{array}{l}\text { Chronic granulomatous } \\
\text { inflammation with caseation; } \\
\text { PCR and AFB negative }\end{array}$ & $\begin{array}{l}\text { Marginal increase } \\
(20 \mathrm{~mm} / \mathrm{h})\end{array}$ & Normal & Positive & 1st-line ATT \\
\hline 4 & 39 years/F & Periostitis & None & $\begin{array}{l}\text { Chronic granulomatous } \\
\text { inflammation with caseation; } \\
\text { AFB positive }\end{array}$ & $\begin{array}{l}\text { Increased } \\
(40 \mathrm{~mm} / \mathrm{h})\end{array}$ & Normal & Positive & 1st-line ATT \\
\hline 5 & 28 years/M & Periostitis & None & $\begin{array}{l}\text { Chronic granulomatous } \\
\text { inflammation with caseation; AFB } \\
\text { negative, PCR positive for MTB }\end{array}$ & $\begin{array}{l}\text { Increased } \\
(42 \mathrm{~mm} / \mathrm{h})\end{array}$ & Normal & Positive & 1st-line ATT \\
\hline 6 & 50 years/F & $\begin{array}{l}\text { Skin ulcer adnexal } \\
\text { tuberculosis }\end{array}$ & None & $\begin{array}{l}\text { Chronic granulomatous } \\
\text { inflammation with caseation; } \\
\text { AFB positive }\end{array}$ & $\begin{array}{l}\text { Increased } \\
(40 \mathrm{~mm} / \mathrm{h})\end{array}$ & Normal & Positive & 1st-line ATT \\
\hline
\end{tabular}

is imaging with computed tomography, biopsy confirmation is recommended in all [2]. The characteristic biopsy finding included chronic granulomatous reaction with giant cells and caseation necrosis. Acid fast bacilli were seen in only two cases. None of the biopsy specimens grew MTb. This could be due to the paucibacillary nature of the disease. PCR on the biopsy sample was positive for MTb in only two out of the four cases in whom the PCR was done. This again could be due to the low sensitivity of the test and the paucibacilliary nature of the disease. In those cases where AFB was negative, it is important to exclude fungal infections as well.

In all our cases, the chest radiography was normal. High-resolution CT thorax probably may be more informative. Treatment requires ATT. Reports of 6 to 18 months of treatment have been described in literature $[3,4]$. However, in an endemic country like ours, a minimum duration of 9 to 12 months is recommended for intraocular tuberculosis [5]. The challenge lies in the compliance in taking the medications. Drug resistance is becoming a serious issue in recent years in India and is a cause of concern. Adequate counselling should form a mandatory part of the treatment.

Surgery may be diagnostic or therapeutic. If diagnosed early and treated adequately, the prognosis is good in these cases $[4,6]$.

The number of cases of different manifestations of orbital tuberculosis in literature [1-16] are highlighted in Table 2 .

\section{Conclusions}

$\mathrm{OTb}$, though rare, should form a part of the differential diagnosis of orbital lesions in a high TB endemic country like ours. Biopsy still remains the mainstay of diagnosis.

\section{Consent}

Written informed consent was obtained from the patient/ $\mathrm{s}$ for the publication of this report and any accompanying images.

Table 2 Types of orbital tuberculosis described in literature with the number of cases

\begin{tabular}{llll}
\hline & Clinical groups of OTB & Number of cases & Total \\
\hline 1. & Classical periostitis & $24[1], 3[7], 1[8]$ & $18[1], 3[7]$ \\
2. & Orbital soft tissue tuberculoma or cold abscess, no bony destruction & $21[1], 1[6], 1[9], 2[10]$ \\
3. & OTB with evidence of bony destruction & $8[1], 1[11]$ & 21 \\
4. & OTB arising from paranasal sinuses & $8[1], 3[10], 1[12], 1[13]$ & 25 \\
5. & Tubercular dacryoadenitis & $1[15]$ & 9 \\
6. & Scrofuloderma orbit and adnexa & $2[14], 1[16]$ & 13 \\
7. & Lupus vulgaris orbit and adnexa & & 3 \\
\hline
\end{tabular}




\section{Abbreviations}

MTb: Mycobacterium tuberculosis; OTb: orbital tuberculosis.

\section{Competing interests}

The authors declare that they have no competing interests.

\section{Authors' contributions}

KB was involved in the conception, design, drafting of the manuscript and revisions. SSB, MM and CJT were involved in the acquisition of data and drafting of the manuscript. All the authors have read and approved the final manuscript.

\section{Acknowledgment}

None.

Received: 10 January 2014 Accepted: 30 April 2014

Published: 22 May 2014

\section{References}

1. Madge SN, Prabhakaran VC, Shome D, Kim U, Honavar S, Selva D (2008) Orbital tuberculosis: a review of the literature. Orbit 27(4):267-277

2. Raina UK, Jain S, Monga S, Arora R, Mehta DK (2004) Tubercular preseptal cellulitis in children. A presenting feature of underlying systemic tuberculosis. Ophthalmology 111:291-296

3. Mortada A (1971) Tuberculoma of orbit and lacrimal gland. B J Ophthalmol 55:565-567

4. Agrawal PK, Nath J, Jain BS (1977) Orbital involvement in tuberculosis, Indian J Ophthalmol 25:12-16

5. Gupta V, Gupta A, Rao NA (2007) Intraocular tuberculosis - an update. Surv Ophthalmol 52:561-587

6. Sethi A, Agrawal AK, Girhotra M, Nithani P (2011) Tuberculosis: an extremely unusual cause of orbital wall erosion. Orbit 30(2):101-102

7. Khurana S, Pushker N, Naik SS, Kashyap S, Sen S, Bajaj MS (2014) Orbital tuberculosis in pediatric population. Trop Doct doi:10.1177/ 0049475514525607

8. Sharma K, Kanaujia V, Jain A, Bains S, Suman S (2011) Tuberculous orbital abscess associated with thyroid tuberculosis. J Ophthalmic Vis Res 6(3):204-207

9. Banait S, Jain J, Parihar PH, Karwassara V (2012) Orbital tuberculosis manifesting as proptosis in an immunocompromised host. Indian J Sex Transm Dis 33(2):128-130

10. Narula MK, Chaudhary V, Baruah D, Kathuria M, Anand R (2010) Pictoral essay: orbital tuberculosis. Indian J Radiol Imaging 20(1):6-10

11. Kar IB, Panda SN, Mishra N, Kar R, Singh AK (2013) Resurgence of tuberculosis: a rare case of primary orbitomaxillary tuberculoma. Oral Surg Oral Med Oral Pathol Oral Radiol 116(1):27-31

12. Chakraborti C, Biswas R, Mondal M, Mukhopadhya U, Datta J (2011) Tuberculous dacryoadenitis in a child. Nepal J Ophthalmol 3(2):210-213

13. Van Assen S, Lutterman JA (2002) Tuberculous dacryoadenitis: a rare manifestation of tuberculosis. Neth J Med 60(8):327-329

14. Bansal S, Sahoo B, Garg VK, Singh S (2013) Periocular lupus vulgaris secondary to lacrimal sac tuberculosis: a rare presentation with emphasis on magnetic resonance imaging in localizing the primary focus of infection. Indian J Dermatol Venereol Leprol 79(3):425-427

15. Sardana K, Koranne RV, Langan U, Sharma RC, Bhatnagar SK (2002) Ocular scrofuloderma with unilateral proptosis. J Dermatol 29(4):232-234

16. El-Ghatit AM, El-Deriny AM, Mahmoud AA, Ashi AS (1999) Presumed periorbital lupus vulgaris with ocular extension. Ophthalmology 106(10):1990-1993

doi:10.1186/1869-5760-4-12

Cite this article as: Babu et al.: Orbital and adnexal tuberculosis: a case series from a South Indian population. Journal of Ophthalmic Inflammation and Infection 2014 4:12.

\section{Submit your manuscript to a SpringerOpen ${ }^{\odot}$ journal and benefit from:}

- Convenient online submission

- Rigorous peer review

- Immediate publication on acceptance

- Open access: articles freely available online

- High visibility within the field

- Retaining the copyright to your article

Submit your next manuscript at $\gg$ springeropen.com 